\title{
A Putative Prohibitin-Calcium Nexus in $\beta$-Cell Mitochondria and Diabetes
}

\author{
Gaurav Verma $\mathbb{D}^{1,2}$ Aparna Dixit $\mathbb{D}^{2},{ }^{2}$ and Craig S. Nunemaker $\mathbb{D}^{3}$ \\ ${ }^{1}$ Molecular Metabolism, Lund University Diabetes Centre, Malmö -21428, Sweden \\ ${ }^{2}$ School of Biotechnology, Jawaharlal Nehru University, -110067, New Delhi, India \\ ${ }^{3}$ HCOM-Biomedical Sciences, Ohio University, Athens Camp, US-45701 Ohio, USA \\ Correspondence should be addressed to Gaurav Verma; gaurav.verma@med.lu.se
}

Received 19 May 2020; Revised 1 August 2020; Accepted 5 August 2020; Published 8 October 2020

Academic Editor: Michaelangela Barbieri

Copyright ( 2020 Gaurav Verma et al. This is an open access article distributed under the Creative Commons Attribution License, which permits unrestricted use, distribution, and reproduction in any medium, provided the original work is properly cited.

The role of mitochondria in apoptosis is well known; however, the mechanisms linking mitochondria to the proapoptotic effects of proinflammatory cytokines, hyperglycemia, and glucolipotoxicity are not completely understood. Complex $\mathrm{Ca}^{2+}$ signaling has emerged as a critical contributor to these proapoptotic effects and has gained significant attention in regulating the signaling processes of mitochondria. In pancreatic $\beta$-cells, $\mathrm{Ca}^{2+}$ plays an active role in $\beta$-cell function and survival. Prohibitin (PHB), a mitochondrial chaperone, is actively involved in maintaining the architecture of mitochondria. However, its possible interaction with $\mathrm{Ca}^{2+}$-activated signaling pathways has not been explored. The present review aims to examine potential crosstalk between $\mathrm{Ca}^{2+}$ signaling and PHB function in pancreatic $\beta$-cells. Moreover, this review will focus on the effects of cytokines and glucolipotoxicity on $\mathrm{Ca}^{2+}$ signaling and its possible interaction with PHB. Improved understanding of this important mitochondrial protein may aid in the design of more targeted drugs to identify specific pathways involved with stress-induced dysfunction in the $\beta$-cell.

\section{Prohibitin: Role in Mitochondrial Function and $\beta$-Cell Physiology}

Mitochondria play a central role in pancreatic $\beta$-cell physiology by coupling glucose to insulin exocytosis [1]. However, mitochondria have emerged as critical players in $\mathrm{Ca}^{2+}$ induced $\beta$-cell death in the context of diabetes [2-5]. $\mathrm{Ca}^{2+}$ has a permissive role in apoptosis but a detailed mechanism of $\mathrm{Ca}^{2+}$-induced apoptosis is not yet defined. Sequestration of $\mathrm{Ca}^{2+}$ by the endoplasmic reticulum (ER) prevents high cytosolic $\mathrm{Ca}^{2+}\left(\mathrm{Ca}^{2+}\right)_{c}$ concentrations. $\mathrm{Ca}^{2+}$ efflux out of the ER can be induced by stresses such as cytokines and glucolipotoxicity [6-8]. High $\left(\mathrm{Ca}^{2+}\right)_{\mathrm{c}}$ can cause mitochondrial dysfunction, which may be mediated via prohibitin (PHB), a mitochondrial scaffold protein. Defects in $\mathrm{ER} \mathrm{Ca}^{2+}$ storage and subsequent mitochondrial dysfunction are associated with the development of diseases like diabetes. It has also been shown that glycogen synthase kinase 3 beta (GSK $3 \beta$ ) mediated Presenilin-1 phosphorylation is responsible for the ER $\mathrm{Ca}^{2+}$ leak in INS- $1 \beta$-cell that affects the mitochondrial functions [9].

PHBs are mitochondrial chaperone proteins recognized for their role in maintaining mitochondrial integrity [10]. Located in the inner mitochondrial membrane, two PHB isoforms, PHB1 and PHB2, form heterodimers to regulate mitochondrial structure and function [11-13]. Investigations with PHBs have established that it plays a crucial role in mitochondrial function in various complex disorders involving $\beta$-cells dysfunction and diabetes [14, 15]. However, the absence of PHBs could also induce the disintegration of mitochondria in nearly all kinds of cells that may lead to apoptosis. The mechanism by which PHB protects against mitochondrial-mediated cell death is not yet understood. As the role of PHB in $\mathrm{Ca}^{2+}$ homeostasis remains to be established, it is still unknown whether PHB function is mediated by $\mathrm{Ca}^{2+}$ signaling which is central to both normal and pathological cellular processes. In this review, we highlight the possible intricate tethering between $\mathrm{PHB}$ and $\mathrm{Ca}^{2+}$ signaling, 
and its role in deciding the fate of pancreatic $\beta$-cells. We discuss different modern approaches that can be used to study the role of $\mathrm{Ca}^{2+}$ signaling in PHB function. We also discuss mitochondrial alterations attributed to the PHB complex with a focus on its implications in $\mathrm{Ca}^{2+}$ regulation and disease pathophysiology. Finally, we have proposed a hypothesized function of $\mathrm{PHB}$ in $\mathrm{Ca}^{2+}$ regulation and its involvement in disease pathophysiology.

\section{A Multifunctional Mitochondrial Protein?}

The eukaryotic mitochondrial PHB complex consists of two heterodimer subunits, PHB1, and PHB2 [10, 12, 16]. PHB1, the principal mammalian $\mathrm{PHB}$, is a potential tumor suppressor due to its antiproliferative action, and therefore named prohibitin [17]. Subsequently, this antiproliferative action was attributed to the $3^{\prime}$-UTR of the mRNA encoding PHB, [18]. PHB2 was characterized by virtue of its dimerization with PHB1.

PHB1 and PHB2, with molecular weights of 32 and $34 \mathrm{kDa}$, respectively, participate to form a ring-like macromolecular structure of $1 \mathrm{MDa}$ at the mitochondrial inner membrane (IM). This high subatomic weight complex has been found in yeast, C. elegans, and mammals [19]. Considering the role of PHB in aging and cancer, assessing their possible role in these processes would be beneficial [20]. The PHBs can form both homodimers as well as heterodimers [21]. The homodimeric interaction of PHBs was not revealed but recent work by Yoshinaka et al. has revealed the PHB2 homodimer with the help of crystal structure that folds into an elongated shape with a highly charged surface. These homodimers exhibited three acidic residues, namely glutamates $\left(\mathrm{E}^{229}, \mathrm{E}^{231}\right.$, and $\left.\mathrm{E}^{233}\right)$, and a glutamine $\left(\mathrm{Q}^{227}\right)$ residue. Substitutions of these residues had no effect on the folding properties and physical hydrophobic interaction between PHBs homodimers but may be instrumental in the formation of mitochondrial interactome [22]. Similar studies have shown evidence of the formation of PHB homodimer in HeLa cells; however, the functional validation of these topology interactions demands further investigations [23]. On contrary, the participation of the PHB heterodimers in various cellular processes is known, but the mechanistic insights are not yet characterized. Having said that PHB1 and PHB2 function as the same heterodimeric complex in mitochondria, it is intriguing that they have differences in their phenotypes [24]. Depletion of either of the subunits results in dissociation of the complex [19]. Around 12 to 16 PHB heterodimers assemble to form a ring-like structure (20-25 nm) in diameter at the mitochondrial (IM) [25]. Extensive research in the field of mitochondrial biology has revealed a significant role of $\mathrm{PHB}$ in various cellular processes. The PHB complex is integrated into the mitochondrial inner membrane matrix through $N$-terminal hydrophobic domain patches. The PHB complex controls mitochondrial membrane protein alteration by m-AAA protease, which works as a holdase or unfoldase chaperone, and facilitates the folding of unfolded membrane proteins. The complex may also play a role in maintaining the mitochondrial genome. PHB complex also assists in mitochondrial morphogenesis by pro- viding a scaffold that recruits membrane proteins to a designated lipid environment.

\section{Diverse Role of Prohibitin in Transcriptional Regulation in Nucleus}

The transcription factor from the E2F family is involved in various biological processes including cell differentiation, proliferation, and apoptosis. It has been shown that PHBs inhibit the E2F transcriptional activity and regulate the cell cycle expression, transcription factors, and nuclear receptors $[26,27]$. However, a detailed mechanism by which these interactions bring about the transcriptional regulatory activity is not yet elucidated. Interactions between PHBs and minichromosome maintenance complex of proteins (MCM2-7) have been shown [28]. Wang et al. [26] have also demonstrated that PHB1 interacts with the cell cycle retinoblastoma proteins $(\mathrm{Rb})$, which are known to inhibit replication in S phase through the attenuation of PCNA function. The $\mathrm{Rb}$-restricting region and another domain mapped to the $C$-terminal part of $\mathrm{PHB}$ are responsible for the suppression of E2F action. PHB interacts with nuclear $\mathrm{p} 53$ to mediate transcription of p53 target genes [29]. In addition, PHB suppresses the activity of transcription factors like E2F1 to E2F5, possibly via the Src activation, and thereby regulates cell proliferation [29]. Mutations present in the $3^{\prime}$-untranslated region of $\mathrm{PHB}$ in breast cancer cells suggest $\mathrm{PHB}$ transcriptionally regulates genes involved in breast cancer development [30]. In addition, PHB2 interacts with the transcription factor family of MyoD and myocyte enhancer element 2 (MEF2), potentially with the help of coactivators such as histone deacetylases HDAC1 [31]. It has been shown that $\mathrm{PHB} 2$ can inhibit muscle differentiation by repressing the transcriptional activity of both MyoD and MEF2. Interestingly, the coexpression of Akt and PHB2 has been shown to prevent the binding of $\mathrm{PHB} 2$ to MyoD. This stimulates muscle differentiation, suggesting that PHB2 may act as a myogenic repressor. Furthermore, PHB specifically binds to the estrogen receptor (ER) with the help of its ligand estradiol, resulting in suppression of ER transcriptional activity [32]. In addition to the ER-binding motif LXXLL near the $N$-terminus, amino acid residues spanning 175-198 in PHBs are required for its interaction with ER [33]. Knockdown of PHB by siRNA blocked the growth inhibitory effect of antiestrogens in MCF-7 breast cancer cells. PHB appeared to suppress androgen receptor-mediated translation and androgen-dependent cell development. These data suggest that PHBs might play important role in determining the sensitivity of estrogen target cells including breast cancer cells. Finally, a binding domain site for the Vitamin D receptor (VDR) has also been recognized in the promoter region of PHB1 [34]. VDR signaling is very important for the chemoprevention of breast cancer cells using Vitamin D analogs. However, the antiproliferative effects of Vitamin D in breast cancer cells are well recognized, but the target genes involved in this process are yet to be identified. Recent reports have suggested that PHB is a Vitamin D target gene and the Vitamin D treatment results in increased cellular PHB1 levels 
[35]. VDR/RXR binding sites are found in the promoter region of PHB gene which makes it a novel Vitamin D target gene involved in the antiproliferative activity. The immense variety and diversity of important nuclear binding partners demonstrate the breadth of PHB function and highlight its action in essential cellular physiology. The main function of the PHB complex is to control proteins involved in the cell proliferation and development, rather than binding to DNA as a transcription factor [36, 37]. All these reports suggest a critical function of PHBs in nuclear transcriptional regulation. Multiple roles of PHB in the nucleus are schematically depicted in (Figure 1).

\section{Multifaceted Role of Prohibitin in Cell Survival and Apoptosis}

Apoptosis, a controlled process of cell death, protects the organism from malfunctioning cells.

Apoptosis may be triggered by different stimuli such as proinflammatory cytokines, UV irradiation, reactive oxygen species (ROS), hormones, and growth factors. Mitochondria play an important role in mediating apoptosis through various signal transduction pathways. As previously mentioned, PHB is a membrane protein with different cellular localizations, and these differences in subcellular localization of PHB may direct what function it plays in the cell. A schematic diagram depicting the subcellular localization of PHB and its multiple functions in regulating cell fate is shown in (Figure 2).

Under stress conditions, PHB translocates to the nucleus and to the mitochondria, where it helps stabilizing the mitochondrial genome and controls mitochondrial morphology, biogenesis, and the intrinsic apoptotic pathway [38]. Differential expression of PHB within cells has a protective mechanism, which prevents the cells from death induced by the chemotherapeutic drug such as camptothecin [39]. Overexpression of PHB in B-cell lymphoma Ramos cells showed a significant decrease in camptothecin-induced cell death compared to parental cells. Levels of $\mathrm{Rb}$ family members that interact with E2F were decreased due to caspase-mediated degradation during camptothecin treatment. However, overexpression of PHB protected cells from cell death, suggesting an anti-apoptotic role. In leukemic cell lines, PHB acts as a nuclear protein substrate [40]. Camptothecin treatment resulted in translocation of PHB out of the nucleus to perinuclear regions [41]. The role of PHBs in cancer is complex. Some types of tumor overexpress PHB1 in the nucleus and some in mitochondria, whereas some of them do not express it at all. Given the existing evidence, fine-tuning of the PHB localization may be beneficial in selectively inducing apoptosis in cancer cells.

PHB acts as a stabilizer of inner mitochondrial membrane proteins. Therefore, loss of PHB severely affects the integrity of the mitochondria, as was shown for the first time in body wall muscle cells of C. elegans. The mitochondrial PHB complex is essential for embryonic viability and germline function in $C$. elegans. Loss of PHB results in mitochondria that appear disintegrated and fragmented [42]. These aspects of mitochondrial fragmentation in PHB deficient cells could be explained by the involvement of OPA1, which regulates the fusion process in mitochondria [36]. Considering PHB plays a crucial role in mitochondrial integrity and architecture, it is plausible that PHB could also participate in mitochondrial DNA (mtDNA) maintenance. This notion is supported by the siRNA-mediated knockdown of PHB1 in HeLa cells resulting in reduced mtDNA copy number, which is largely regulated by mitochondrial transcription factor A (TFAM) [43, 44]. PHB also correlates with oxidative stress and affects electron transport chain complex activity. However, the role PHB plays in regulating ROS production is currently not understood. The binding of PHB to mtDNA could explain these phenomena given $\mathrm{mtDNA}$ encodes oxidative phosphorylation (OXPHOS) subunits. PHBs play an important role in mitochondrial membrane integrity; therefore, it is possible that depletion of $\mathrm{PHB}$ could result in deficient OXPHOS activity.

Oxidative stress has been the main cause in the manifestation of various complex disorders including myocardial injury, diabetes, and neurodegenerative disorders [45-47]. Oxidative stress in aging mitochondria also leads to the accumulation of superoxide, which has been attributed as one of the major causes of mitochondrial dysfunction. Generation of mitochondrial ROS (mtROS) in T2D could be manifested by various mechanisms in which one of them is mitochondrial membrane potential $(\Delta \Psi \mathrm{m})$. PHBs along with a mitochondrial anion carrier protein uncoupling protein 2 (UCP2) reduces this $\triangle \Psi \mathrm{m}$ and regulate the levels of mtROS and could be used as a biomarker surrogate for vascular health in patients with and without T2DM [48]. This PHBUCP2 axis could also be one of the potential biomarkers that need to be investigated and further extrapolated as a disease biomarker. Having said that, PHB harbors diverse arrays of signaling, and its potential as therapeutics could be attributed by investigating its interacting partners like $\left(\mathrm{Ca}^{2+}, \mathrm{ROS}\right.$, and ATP) in a particular disease state. Furthermore, superoxide activates UCP2 that leaks the apoptosis-triggering protein cytochrome $\mathrm{C}$ from the inner mitochondrial membrane space when activated [49]. While the role of $\mathrm{PHB}$ as a mitochondrial chaperone has been characterized $[50,51]$, its role in oxidative stress has not been elucidated. PHB levels are elevated during oxidative stress, and overexpression of PHB significantly reverses this oxidative stress effect. Additionally, hydrogen peroxide $\left(\mathrm{H}_{2} \mathrm{O}_{2}\right)$-induced apoptosis was prevented in PHB-overexpressing cardiomyocytes [52].

It is possible that PHB promotes the mitochondrial membrane permeability transition and inhibits the release of cytochrome $\mathrm{c}$ from mitochondria to trigger apoptosis. These studies reflect the protection conferred against oxidative stress-induced apoptosis that has been reported in various mitochondrial complex disorders. These data indicate that $\mathrm{PHB}$ protects from oxidative stress-induced damage, and fine tuning of PHB content in mitochondria could be a potential new therapeutic target for myocardial injury and diabetes. Therefore, considering the PHB participation in integral signaling of mitochondrial-mediated cellular disturbance, it is plausible that targeting PHB may inhibit the progression and pathology of diseases characterized by oxidative stress. However, it has also been reported that the treatment of prostate cancer cells with TGF- $\beta$ results in translocation of PHB from the nucleus to the cytosol where it strongly associates with the mitochondrial apoptosis-suppressor $\mathrm{Bcl}-2$ and 


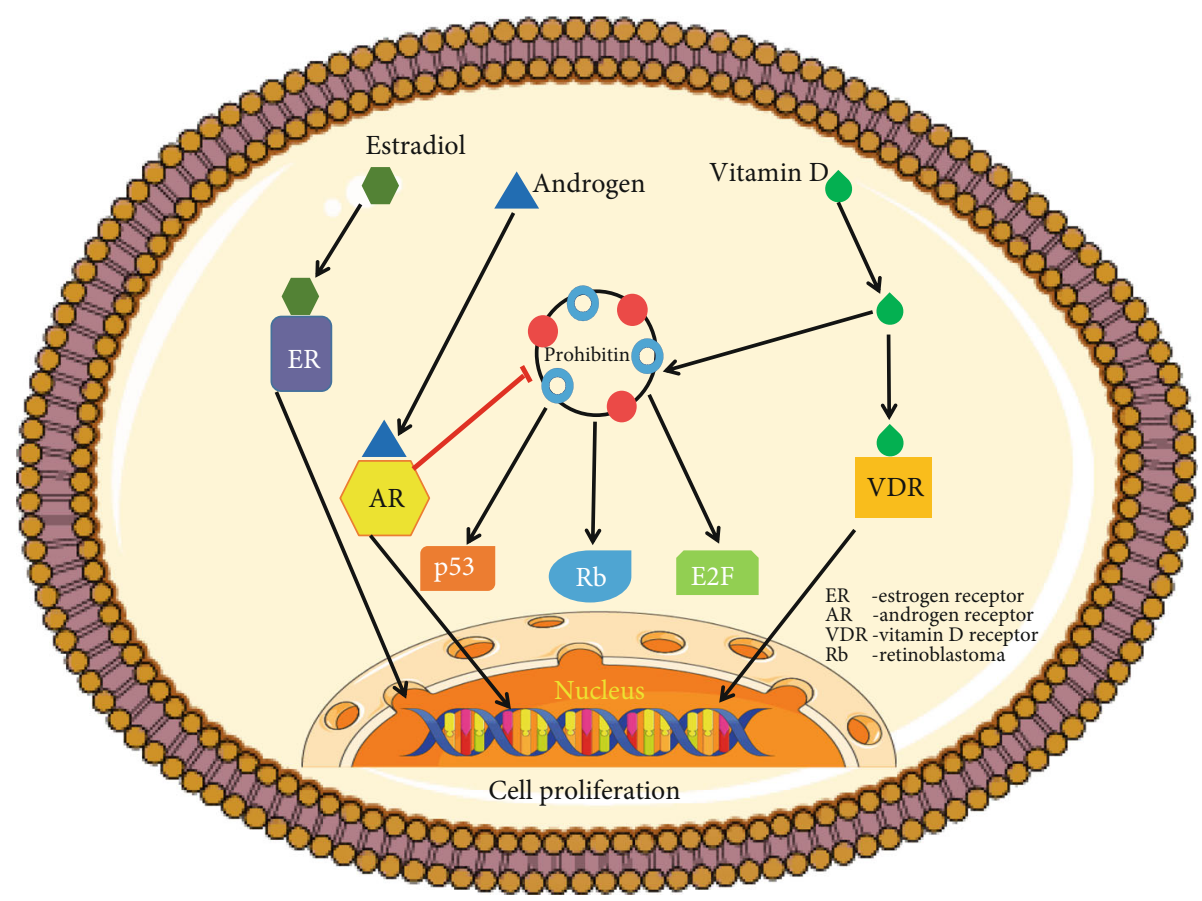

FIgURE 1: Prohibitins as gene expression regulators of the cell. Prohibitin complex interact with nuclear receptors, like ER, AR, VDR, and transcription factors $\mathrm{p} 53, \mathrm{Rb}$, and $\mathrm{E} 2 \mathrm{~F}$ thereby regulate gene expression and cell proliferation of the target cell.

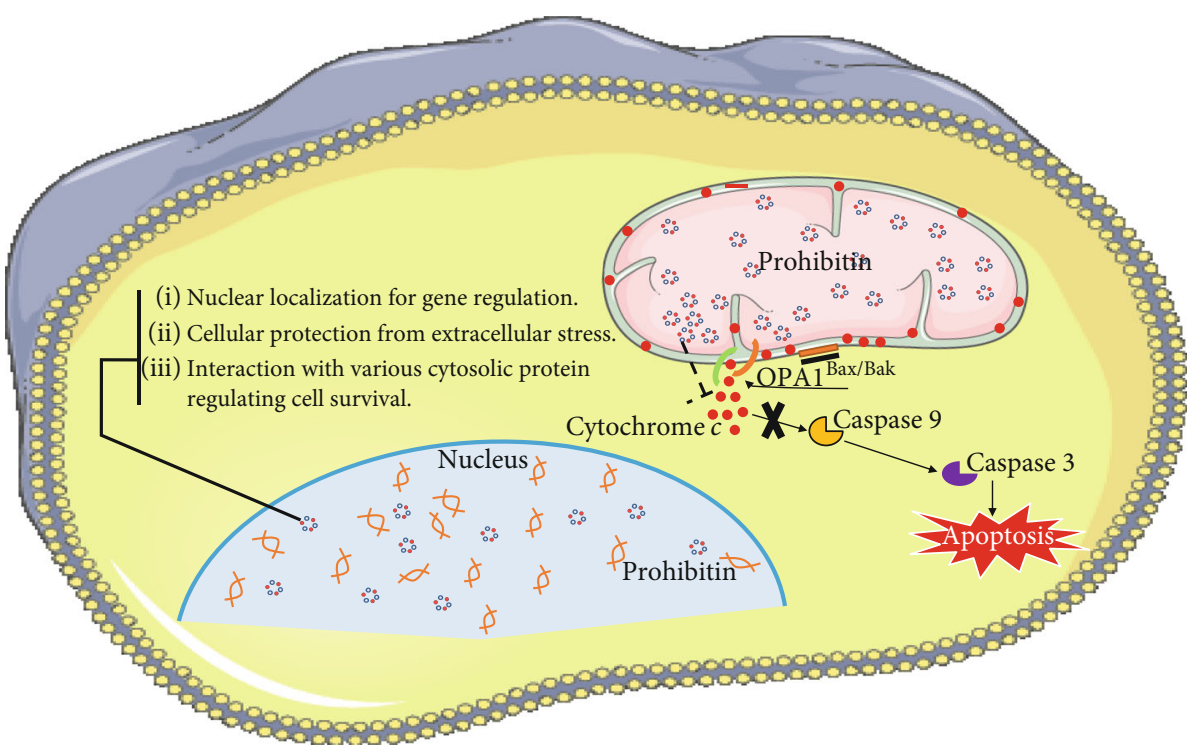

Figure 2: Putative role of prohibitin in mitochondria and nucleus. As mitochondrial chaperones, PHBs preserve the integrity of mitochondria. Their translocation to nucleus promotes binding of nuclear receptors and exhibits their action in the nucleus. PHBs interact with mitochondrial regulators including the key players of apoptotic pathways. PHBs interact with OPA1 complex (green and orange) which is located at the mitochondrial cristae junctional openings. Remodelling of these cristae majorly by OPA1 complex proteolysis or intermembrane proteases releases the cytochrome $c$ in the cytosol. OPA1-mediated cristae opening is Bax/Bak dependent which is required for the cytochrome $c$ release. Cytochrome $c$ further activates the downstream effector molecules like caspase 9 and caspase 3 that culminates into apoptosis. Our hypothesized model proposes that overexpression of PHB could stabilize the mitochondrial structure and morphology that in turn may prevent the release of cytochrome $c$, activation of caspase, and apoptosis.

represses its activity [53]. All these findings suggest that PHB has a diverse array of signaling, and its function may depend on the type of stimulus the cells encounter. Mitochondrial dysfunction in these stressed cells can give rise to a broad spectrum of diseases such as neurodegenerative disorders, cardiomyopathies, optic neuropathy, and inflammatory diseases. During cellular stress, PHB can translocate to the nucleus or to the mitochondria and could possibly trigger apoptotic signals [54]. How a membrane protein such as PHB that can control cell death requires future studies. That 
is to say, it is possible that PHB not only functions as a transmembrane receptor in the cell but could also be acting as a regulator between cell survival and cell death; although, this is an area that requires further investigation.

\section{Prohibitin-Ca ${ }^{2+}$ Interface: Possible ER- Mitochondria $\mathrm{Ca}^{2+}$ Juxtapose}

Positively charged $\mathrm{Ca}^{2+}$ ions are one of the primary signaling elements found within cells. In almost all membrane bound organelles, $\mathrm{Ca}^{2+}$ binds to hundreds of proteins to impact changes in localization, association, and function [55]. It is also an important second messenger participating in many cellular activities including cell growth, differentiation, gene regulation, and cell survival $[56,57] . \mathrm{Ca}^{2+}$ helps in reversing the damage elicited by cellular insults by both facilitating cell survival and mitigating cell death responses. Interestingly, in the process of adaptive responses, $\mathrm{Ca}^{2+}$ participates as a crucial second messenger that decides whether a cell must survive or die. This duality of $\mathrm{Ca}^{2+}$ function makes it difficult to delineate mechanisms required for $\mathrm{Ca}^{2+}$-mediated control of cell survival and apoptosis. In the pancreatic $\beta$-cells, it is important to determine the source of the disruption in $\mathrm{Ca}^{2+}$ signaling that ultimately affects the overall $\beta$-cell function. Researchers have also proposed the role of mitochondria in such events; however, its involvement in this process remains poorly understood. One of the most important questions to-date in the field is understanding the role that PHBs might play with ER and mitochondrial $\mathrm{Ca}^{2+}$ storage. However, untill now, $\mathrm{PHBs}$ are not known to regulate $\mathrm{Ca}^{2+}$, but it has been shown that $\mathrm{PHB} 2$ regulates the $\mathrm{Mg}^{2+}$ channel Transient Receptor Potential Melastatin 6 (TRPM6) [58]. TRPM6 functions as the gatekeeper of transepithelial $\mathrm{Mg}^{2+}$ transport and regulation by $\mathrm{PHB}$ hints the role of $\mathrm{PHBs}$ in the possible interaction with the divalent cationic molecule like $\mathrm{Ca}^{2+}$. In this section, we will review the kinetics of $\mathrm{Ca}^{2+}$ as an indicator of $\beta$-cell function and explain the effect of proinflammatory cytokines on $\mathrm{Ca}^{2+}$ oscillation in $\beta$-cells. Cytokines induce a disruption in $\mathrm{Ca}^{2+}$ signaling that can impair insulin release in response to glucose stimulation, and in chronic cases, can even lead to $\beta$-cell death. In particular, IL- $1 \beta$ can alter intracellular $\mathrm{Ca}^{2+}$ levels by depleting $\mathrm{Ca}^{2+}$ from the ER via $\mathrm{Ca}^{2+}$ channels such as inositol 1,4,5-trisphosphate receptor $\left(\mathrm{IP}_{3} \mathrm{R}\right)$, Ryanodine receptor (RYR), and sarco/endoplasmic reticulum $\mathrm{Ca}^{2+}$-ATPase (SERCA) pump.

These ER $\mathrm{Ca}^{2+}$ channels can in turn facilitate the increase in $\mathrm{Ca}^{2+}$ flux to the cytosol following its sequestration in cellular organelles such as mitochondria [59]. Sudden elevation of mitochondrial $\mathrm{Ca}^{2+}\left(\mathrm{Ca}^{2+}\right)_{\mathrm{m}}$ can lead to $\mathrm{Ca}^{2+}$ toxicity and trigger apoptosis. It is now widely accepted that depletion of $\mathrm{Ca}^{2+}$ levels leads to protein misfolding and activation of the unfolded protein response (UPR) [60]. Organelles such as the ER, mitochondria, and nucleus are also affected by cytokine like IL- $1 \beta$ which may lead to $\beta$-cell death in type 1 diabetes (T1D) and type 2 diabetes (T2D). IL- $1 \beta$-induced changes in the level of the $\mathrm{Ca}^{2+}$ in the ER and cytosol, and its resulting impact on mitochondrial physiology like mito- chondrial membrane potential $(\Delta \Psi \mathrm{m})$ are depicted in (Figure 3). As evident from (Figure 3), IL-1 $\beta$ treatment results in a time-dependent increase in $\left(\mathrm{Ca}^{2+}\right)_{\mathrm{c}}$ as measured by Fluo- 4 with a concomitant increase in $\Delta \Psi \mathrm{m}$ by TMRM. Analysis of the ER in the IL- $1 \beta$-treated cells shows an increase in ER size, suggesting ER attempts to mitigate the effect of IL- $1 \beta$ by increasing its biogenesis. It is important to further study $\mathrm{Ca}^{2+}$ signaling in these compartments, which could be a worthy area of investigation in both normal and pathological cellular processes.

\section{Studying Prohibitin-Ca ${ }^{2+}$ Signaling with Live Cell Imaging: A Boon for $\mathrm{Ca}^{2+}$ Studies}

Using the live-cell imaging technology coupled with focused fluorescent dyes, the effect of proinflammatory cytokines on $\mathrm{Ca}^{2+}$ flux in pancreatic $\beta$-cells has been extensively studied $[61,62]$. Numerous reports have implicated $\mathrm{Ca}^{2+}$ oscillation as critical in ER and mitochondria to maintain pancreatic physiology $[63,64]$. Extensive research demonstrates that $\mathrm{Ca}^{2+}$ is confined to particular regions of pancreatic $\beta$-cells, principally in the ER, and mitochondria $[65,66]$. Likewise, observed $\mathrm{Ca}^{2+}$ movements from the ER to mitochondria are induced by cytokines that promote mitochondrial dysfunction and cell death [67]. As stated earlier, the role of PHB in controlling mitochondrial structural integrity, and subsequently $\beta$-cell capacity, has been studied extensively; however, there has been no experimental evidence that suggests the possible role of $\mathrm{PHB}$ in the regulation of $\mathrm{Ca}^{2+}$ signaling in $\beta$-cell mitochondria. Given that $\mathrm{PHB}$ is a mitochondrial chaperone and could regulate $\mathrm{Ca}^{2+}$ in $\beta$-cell physiology, we hypothesize $\mathrm{PHB}$-mediated regulation of $\mathrm{Ca}^{2+}$ could play a role in the $\beta$-cell function.

\section{Prohibitin-Ca ${ }^{2+}$ Signaling Crosstalk: Potential Candidate in $\beta$-Cell Dysfunction}

Understanding the role of $\mathrm{PHB}$ in $\mathrm{Ca}^{2+}$ regulation will aid in the understanding of the mitochondrial capacity and dysfunction in metabolic pathologies like diabetes. Recent reports suggest that $\beta$-cells from $\mathrm{PHB}^{-1-}$ mice display a varing degree of mitochondrial dysfunction immediately after cell subculture [68]. Cytokine or glucolipotoxicity induced changes in $\mathrm{Ca}^{2+}$ levels enhance $\mathrm{Ca}^{2+}$ flux out of the ER through $\mathrm{ER} \mathrm{Ca}^{2+}$ channels, thereby diminishing the $\mathrm{Ca}^{2+}$ pool stored in the ER. Cellular stressors like cytokines, oxidative stress, and hyperglycemia impair the storage capacity of the ER, resulting in elevated $\left(\mathrm{Ca}^{2+}\right)_{\mathrm{c}}$ and subsequent mitochondrial dysfunction. Given that $\mathrm{PHB}$ is a mitochondrial chaperone, it is possible that $\mathrm{PHB}$ participates in $\mathrm{Ca}^{2+}$ buffering during $\left(\mathrm{Ca}^{2+}\right)_{\mathrm{c}}$ elevation. Depletion of $\mathrm{PHB}$ could result in adverse effects associated with elevated $\left(\mathrm{Ca}^{2+}\right)_{\mathrm{c}}$ levels. The outline of the current hypothesis is depicted in (Graphical Abstract) and in (Figure 4). However, the role of $\mathrm{Ca}^{2+}$ in PHB-mediated maintenance of mitochondrial function in pancreatic $\beta$-cells, and how $\mathrm{PHB}$ may mitigate future risk of T2D is not yet explored; additional studies investigating this process are needed to aid in the development of therapeutics for diabetes. 
IL-1 $\beta(2 \mathrm{ng} / \mathrm{ml}), 0 \mathrm{hr}$

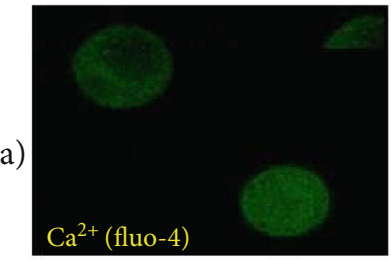

(b)

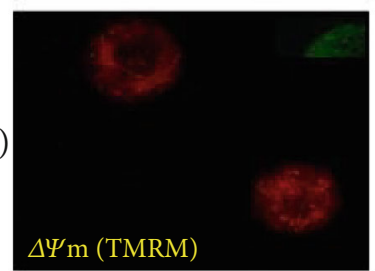

(c)

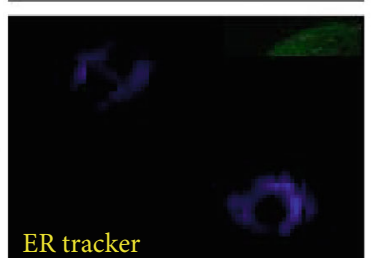

(d)

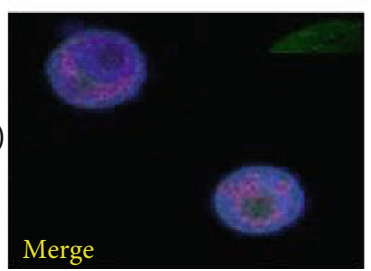

$\mathrm{IL}-1 \beta(2 \mathrm{ng} / \mathrm{ml}), 1 \mathrm{hr}$
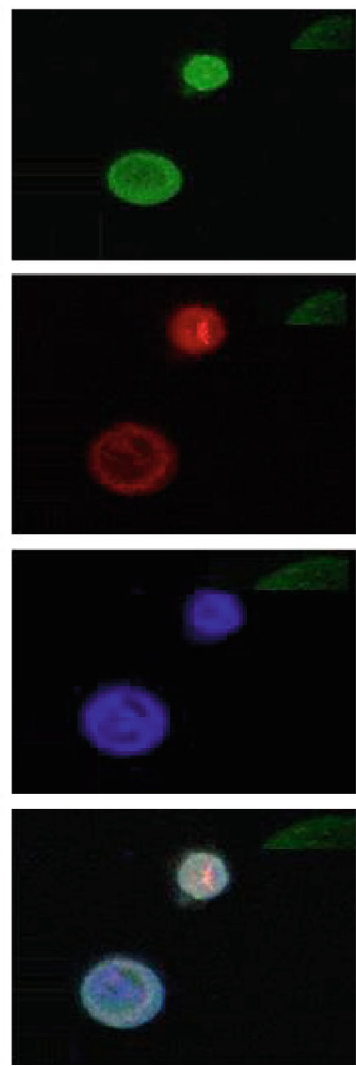

IL- $1 \beta(2 \mathrm{ng} / \mathrm{ml}), 2 \mathrm{hr}$
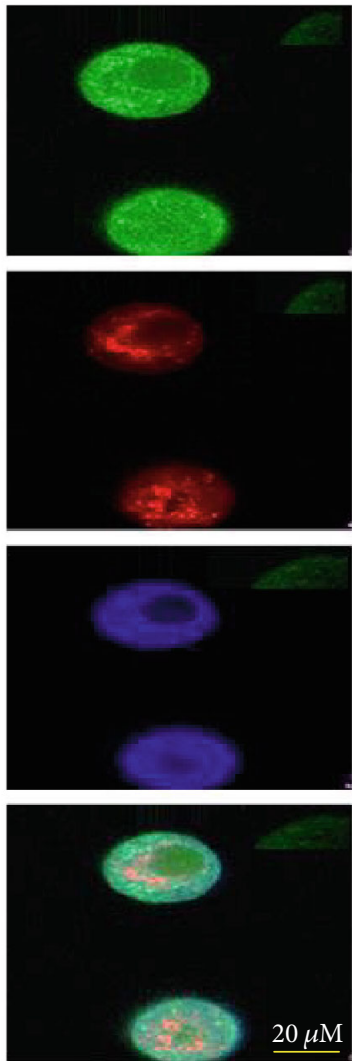

FIGURE 3: Fluorescent imaging of $\beta$-cells with Fluo-4, TMRM, and ER tracker. Mice islets were isolated and dissociated in $\beta$-cells. Further, $\beta$ cells were induced by IL-1 $\beta(2 \mathrm{ng} / \mathrm{ml})$ for $0 \mathrm{hr}, 1 \mathrm{hr}$, and $2 \mathrm{hr}$, respectively, and were processed for $\mathrm{Ca}^{2+}$ imaging with respective fluorescent dyes. Panel shows differential expression of $\mathrm{Ca}^{2+}$ level in different compartments of the cell. Panel (a) shows the level of cytosolic Ca ${ }^{2+}$ as measured by Fluo-4 (green), panel (b) shows the $(\Delta \Psi \mathrm{m})$ with TMRM (red), panel (c) shows the endoplasmic reticulum with ER tracker (blue), and the merged image of all three fluorescence are represented in panel (d). Leica live cell imaging microscope was used to perform the imaging.

In the following section, experimental approaches to monitor $\mathrm{Ca}^{2+}$ flux in $\beta$-cells and the role PHB plays in regulating $\mathrm{Ca}^{2+}$ flux will be discussed. To date, confocal and live cell microscopes are the most commonly used approach to evaluate $\mathrm{Ca}^{2+}$ oscillation in live cells. Cellular stressors (cytokines and hyperglycemia) impair $\mathrm{Ca}^{2+}$ flux in living $\beta$-cells, of which the immediate impact on PHB function can be easily monitored with the help of genetically encoded $\mathrm{Ca}^{2+}$ indicators (GECI), $\mathrm{Ca}^{2+}$ dyes and fluorescence microscopy. These commercially available indicators are widely used to determine localization of $\mathrm{Ca}^{2+}$. To accurately measure the $\mathrm{Ca}^{2+}$ flux changes in $\beta$-cells after stress induction, different combinations of fluorophores can be used to identify the subcellular region that exhibits fluorescent emission upon laser stimulations [69, 70]. Fluorescent markers like 4mtD3cpV (mitochondrial FRET-based $\mathrm{Ca}^{2+}$ sensor), D1ER [secondgeneration cameleon (calcium sensor) targeted to ER], and fluo-4/FURA-2AM can be used to evaluate $\mathrm{Ca}^{2+}$ oscillations in mitochondria, ER, and cytosol, respectively [71]. In most studies involving diabetes, either a combination of cytokines such as TNF- $\alpha$, IL- $1 \beta$, and IFN $\gamma$ or $15-30 \mathrm{mM}$ glucose mimicking hyperglycemia may be used to stimulate $\mathrm{Ca}^{2+}$ release from the ER. Cellular stress results in altered $\mathrm{Ca}^{2+}$ signaling thereby promotes mitochondrial dysfunction and ultimately culminate in apoptosis.

Despite the lack of evidence directly linking $\mathrm{PHB}$ to $\mathrm{Ca}^{2+}$ flux, PHB has been implicated in both $\beta$-cell and mitochondrial physiology. $\beta$-cell specific PHB2 knockout mice $(\beta$ $\mathrm{PHB}^{-l-}$ ) have dysfunctional mitochondria, enhanced $\beta$-cell death, and diabetes [68]. However, it remains to be observed how this mitochondrial chaperone participates in handling $\mathrm{Ca}^{2+}$ toxicity and to what extent the $\mathrm{Ca}^{2+}$ burden imposed by the cellular insults is mitigated by PHB? PHB serves as a chaperone ensuring the correct order of the protein translation machinery in the cell. It is therefore imperative to study its role in this phenomenon. Given that the majority of chaperones require $\mathrm{Ca}^{2+}$ for their function $[72,73]$, we hypothesize that $\mathrm{PHB}$ could be a plausible candidate in sequestering excess $\left(\mathrm{Ca}^{2+}\right)_{\mathrm{m}}$, inhibiting the execution of apoptosis by mitochondria. Primarily, mitochondria sequester the $\left(\mathrm{Ca}^{2+}\right)_{\mathrm{c}}$ by inner mitochondrial membrane (IMM) mitochondrial calcium uniporter (MCU) in cooperation with voltage dependent anion channel (VDAC) which is expressed at the outer mitochondrial membrane (OMM) surface (Figure 4). It is also interesting to note that PHBs interact with VDAC [74] and since VDAC is majorly 


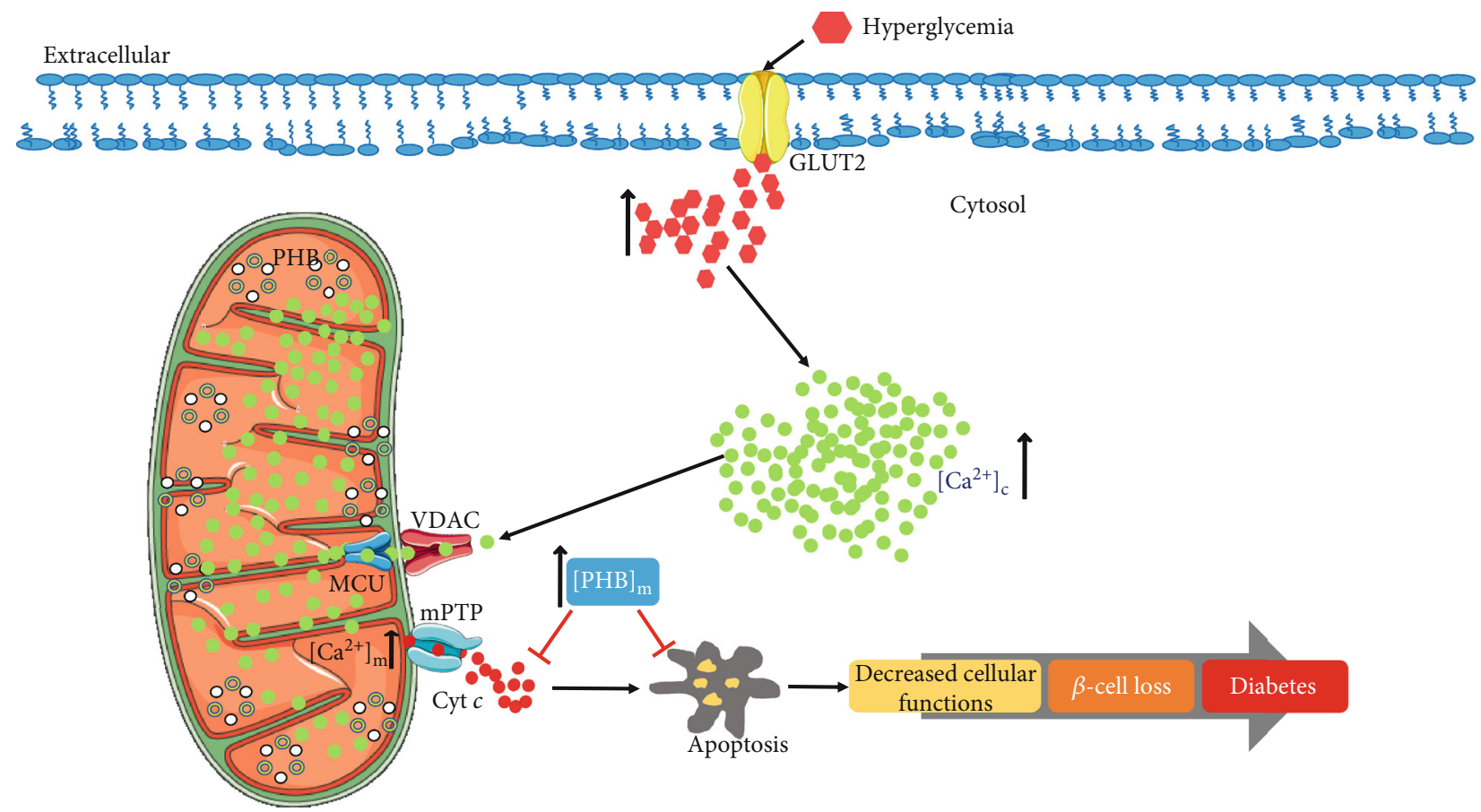

FIgURE 4: Plausible role of prohibitin in mitochondrial $\mathrm{Ca}^{2+}$ overload. During hyperglycemic condition, there is a remarkable increase in cytosolic $\mathrm{Ca}^{2+}\left(\mathrm{Ca}^{2+}\right)_{\mathrm{c}^{\prime}}$. Physiologically, the elevation of $\left(\mathrm{Ca}^{2+}\right)_{\mathrm{c}}$ is required for maintaining the normal metabolic pathways; however, persistent elevation leads to the movement of the $\left(\mathrm{Ca}^{2+}\right)_{\mathrm{c}}$ to the mitochondria and the subsequent rise in mitochondrial $\mathrm{Ca}^{2+}\left(\mathrm{Ca}^{2+}\right)_{\mathrm{m}}$ concentration. Prohibitin may attempt to buffer this excess of $\left(\mathrm{Ca}^{2+}\right)_{\mathrm{m}}$ to further prevent the mitochondrial-mediated apoptosis by preventing the release of cytochrome $c(\mathrm{Cyt} c)$. The consequence of this event may lead to decreased cellular function, $\beta$-cell loss, and diabetes. Overexpression of prohibitin may help in sequestering excess of the $\mathrm{Ca}^{2+}$ and prevent apoptosis. Mitochondrial calcium uniporter $(\mathrm{MCU})$ and voltage-dependent anion channel (VDAC) are the channels on the inner and outer surface of mitochondria that sequesters the $\left(\mathrm{Ca}^{2+}\right)_{\mathrm{m}}$ cooperatively.

involved in the permeability pathways that control the flow of $\mathrm{Ca}^{2+}$, it is very likely that PHBs could regulate the $\mathrm{Ca}^{2+}$ signaling both dependent and independent of VDAC. The mitochondrial architecture and its morphology are principally maintained by the coordination of organellar and cytosolic communication. The involvement of $\mathrm{Ca}^{2+}$ signaling in the regulation of mitochondrial morphology in physiological and pathological conditions remains to be understood. Nevertheless, there are reports demonstrating $\mathrm{Ca}^{2+}$ playing a more central role in orchestrating these processes than previously understood [75].

We, therefore, postulate that excess $\mathrm{Ca}^{2+}$ in the mitochondria could be sequestered by overexpression of PHBs, which in turn could prevent the induction of cell death or other pathological conditions. To better understand the role PHB plays in $\mathrm{Ca}^{2+}$ signaling, several approaches could be employed. For example, studying ER $\mathrm{Ca}^{2+}$ channels in partial knockdown of PHB could help distinguish the role of these channels in $\mathrm{Ca}^{2+}$ release.

Overexpression or knockdown of PHBs can reveal the degree to which $\mathrm{PHB}$ contributes to mitochondrial $\mathrm{Ca}^{2+}$ overburden, and further, delineate the role of PHB in buffering the elevated $\mathrm{Ca}^{2+}$. This will aid in understanding the link between $\mathrm{PHB}$ and $\mathrm{Ca}^{2+}$ homeostasis in cellular physiology. Blocking $\mathrm{Ca}^{2+}$ channels using $\mathrm{Ca}^{2+}$ channel blockers and monitoring the expression of PHBs would be a simple and valuable experiment in testing the hypothesis that $\mathrm{PHB}$ regu- lates $\mathrm{Ca}^{2+}$ exchange between the ER and mitochondria, particularly in $\beta$-cells. Alternatively, a more significant experiment would be to examine whether different types of PHB ligands regulate $\mathrm{Ca}^{2+}$ flux as described by Wang et al. [76]. In the context of $\mathrm{Ca}^{2+}$-PHB orchestration, an optional methodology of cameleon test (genetically encoded fluorescent markers for $\mathrm{Ca}^{2+}$ ) could also be utilized for monitoring of $\mathrm{Ca}^{2+}$ movement in different cell types [77]. Cameleon tests like D1ER and $4 \mathrm{mtD} 3 \mathrm{cpV}$ are very efficient to perform FRET-based imaging to monitor alterations in $\mathrm{Ca}^{2+}$ levels induced by cytokines or glucolipotoxicity challenges. Such experiments would help in characterizing the phenomena involving $\mathrm{Ca}^{2+}$ levels and PHB capacity to prevent $\beta$-cell death.

\section{Role of Prohibitin in Membrane Signaling and Cellular Fate: A Binary Switch?}

PHBs are located in various membranes where they play an instrumental role in cellular signaling. PHBs are engaged in the tyrosine phosphorylation PI3K/Akt, MAPK/ERK pathways, and TGF $\beta$ signaling pathways, suggesting the importance of $\mathrm{PHB}$ in processes such as metabolism, proliferation, and development [78]. PHB has also been shown to be required for the Ras-mediated Raf-MEK-ERK activation, a critical process that occurs in conjunction with the plasma membrane [79]. PHB can also indirectly facilitate 
TABLE 1

\begin{tabular}{|c|c|c|c|c|}
\hline PHB1 function & Location & $\begin{array}{l}\text { Subcellular } \\
\text { localization }\end{array}$ & Pathophysiology & Reference \\
\hline $\begin{array}{l}\text { Oxidative stress } \\
\text { regulation }\end{array}$ & $\beta$-Cells & Mitochondria & Type 2 diabetes & Lee et al., FEBBS J, 2010. \\
\hline $\begin{array}{l}\text { Oxidative stress } \\
\text { regulation }\end{array}$ & $\begin{array}{l}\text { Intestinal epithelial } \\
\text { cells }\end{array}$ & Mitochondria & $\begin{array}{l}\text { Inflammatory bowel } \\
\text { disease }\end{array}$ & Kathiria e al., Plos One, 2010. \\
\hline$\alpha$-SMA regulation & Renal cells & Mitochondria & $\begin{array}{l}\text { Tubulointerstitial } \\
\text { lesions }\end{array}$ & $\begin{array}{l}\text { Zhou et al., J of Recep and Signal Trans, } \\
2013 .\end{array}$ \\
\hline $\begin{array}{l}\text { Oxidative stress } \\
\text { regulation }\end{array}$ & Cardiomyocytes & Mitochondria & Myocardium damage & Liu et al., Cell Stress Chaperone, 2009. \\
\hline $\begin{array}{l}\text { Oxidative stress } \\
\text { regulation }\end{array}$ & Hepatocytes & Mitochondria & $\mathrm{HCV}$ & Ivanov et al., Viruses, 2013. \\
\hline $\begin{array}{l}\text { Combating } \\
\text { inflammation }\end{array}$ & Lungs & Mitochondria & COPD & Soulitzis et al., Resp. Med, 2012. \\
\hline $\begin{array}{l}\mathrm{P}-53, \mathrm{Rb} \text { tumor } \\
\text { regulator }\end{array}$ & Cancer cells & Nucleus & Cancer & Fusaro et al., JBC, 2003. \\
\hline Synaptic movement & Neural cells & Mitochondria/nucleus & Schizophrenia & Bemstein et al., Neuromol Med, 2012 \\
\hline
\end{tabular}

the crosstalk between the PI3K/Akt and Ras/MAPK/ERK pathways mediated by its signaling intermediates PtdIns $(3,4,5) \quad P_{3}$, SH2-domain containing phosphatase (Shp)1 [80]. PHB has also been shown to be the intracellular effector molecule of TGF- $\beta$ signaling in prostate cancer cells. Loss of $\mathrm{PHB}$ also culminates in apoptosis via the TGF- $\beta$-Smad axis suggesting its role in cellular apoptosis [53]. PHB levels vary under different stimuli, and it can be said that it acts as both a proapoptotic as well as antiapoptotic molecule, depending upon the type of stress the cell has encountered with. It is reported that oxidative stress induces deleterious effects in pancreatic $\beta$-cells $[81,82]$.

However, PHB expression in pancreatic $\beta$-cells is protective against oxidative stress and apoptosis [83]. Furthermore, we previously reported, IL- $1 \beta$, a pro-inflammatory cytokine induces ER stress and mitochondrial-mediated apoptosis in pancreatic $\beta$-cells. This action is mediated by JNK, and in part, by $\mathrm{Ca}^{2+}$ [59]. In addition, mitochondrial architecture is primarily governed by the integration of organellar and functional protein crosstalk. Mitochondria help in buffering excess $\left(\mathrm{Ca}^{2+}\right)_{\mathrm{c}}$ and maintain the appropriate $\mathrm{Ca}^{2+}$ level in the cells [84]. During stress, mitochondrial strength is compromised which in turn leads to mitochondrial $\mathrm{Ca}^{2+}$ overload and apoptosis in pancreatic $\beta$-cells. PHB stabilizes mitochondrial proteins by functioning as a chaperone. The majority of chaperones need $\mathrm{Ca}^{2+}$ to function $[85,86]$. However, the role of $\mathrm{Ca}^{2+}$ in regulation of mitochondrial PHB in both normal and pathological conditions is not known. Recent reports have suggested that $\mathrm{Ca}^{2+}$ plays a critical role in maintaining mitochondrial health and proper function $[87,88]$. Given both $\mathrm{PHB}$ and $\mathrm{Ca}^{2+}$ are critical players in mitochondrial dynamics, it is possible that a crosstalk exists between $\mathrm{PHB}$ and $\mathrm{Ca}^{2+}$. $\mathrm{PHB}$, a stabilizer of inner mitochondrial membrane proteins, may participate in $\mathrm{Ca}^{2+}$ handling in the mitochondria, thereby preventing mitochondrial $\mathrm{Ca}^{2+}$ overload which is a critical instigating event of pancreatic $\beta$-cell death. In an event of increased $\left(\mathrm{Ca}^{2+}\right)_{\mathrm{c}}$, the mitochondria make efforts to buffer elevated $\left(\mathrm{Ca}^{2+}\right)_{\mathrm{c}}$, possibly by fine-tuning PHB levels. Such fine-tuning by mitochondria may protect the cell from deleterious events such as altered membrane potential, impaired ATP production, deficiency in insulin secretion, and $\beta$-cell death. However, the exact role of PHB in handling excess $\mathrm{Ca}^{2+}$ in mitochondria is not known. Therefore, PHB may be a potential molecular target that may be manipulated pharmacologically to treat obesity and diabetes. Recent reports involving the role of $\mathrm{PHB}$ in obesity draws attention to investigate this axis [89, 90]. Of note, $\mathrm{PHB}$ expression has to be modulated physiologically which is otherwise may lead to other serious consequences like obesity and glucose homoeostasis imbalance. It is very interesting to note that almost 25 years ago, McClung et al. [91] speculated prohibitin as an inner mitochondrial membrane protein, which may control ion transport and calcium-dependent ATP production, but surprisingly, there has been no experimental evidence that demonstrates $\mathrm{Ca}^{2+}$ regulated $\mathrm{PHB}$ function in mitochondria. The possible role of PHB and its role in disease pathology is described in (Table 1).

\section{Methods Involved in Calcium Signaling: An Era of Modern Biology}

Genetically, manipulating PHB expression in both commercially available pancreatic $\beta$-cells and human islets would provide a more robust model in which $\mathrm{PHB}$ function in $\mathrm{Ca}^{2+}$ homeostasis may be interrogated. $\mathrm{Ca}^{2+}$ signaling may be manipulated intracellularly via commercially available thapsigargin, an ER stress inducer used to discharge $\mathrm{Ca}^{2+}$ into the cytosol. To determine how PHBs contribute to $\mathrm{Ca}^{2+}$ buffering, mitochondrial targeted GECI like $4 \mathrm{mtD} 3 \mathrm{cpV}, \mathrm{mtGeCo1}$, and $\mathrm{mt}$ Pericam can be used to monitor the continuous movement of $\left(\mathrm{Ca}^{2+}\right)_{\mathrm{m}}$.

The respective fluorescence of these GECI in the mitochondria will delineate the capacity of PHBs to buffer excess $\left(\mathrm{Ca}^{2+}\right)_{\mathrm{m}}$. To fully understand these phenomena, experiments 
performed in $\beta$-cells $\mathrm{PHB}^{-/-}$mice (and their control littermate $\beta$-PHB2 ${ }^{\mathrm{H} / \mathrm{fl}}$ ) can be used to provide in vivo evidence. Overexpression of PHBs in $\beta$-cells can aid in evaluating $\left(\mathrm{Ca}^{2+}\right)_{\mathrm{m}}$ overload, a hallmark feature in mitochondrialmediated pancreatic $\beta$-cell death. Additional analysis using patch-clamp electrophysiology (current and voltage clamps) can also be used to evaluate $\mathrm{Ca}^{2+}$ homeostasis as an alternative approach to investigate PHB capacity of buffering excess $\left(\mathrm{Ca}^{2+}\right)_{\text {c }}$.

Proinflammatory cytokines, hyperglycemia, and glucolipotoxicity all alter $\mathrm{Ca}^{2+}$ levels such that the activated signaling cascades promote pancreatic $\beta$-cell death during diabetes. However, the mechanisms contributing to the proapoptotic effects of such stressors are not completely understood. In addition to the seminal discovery of the core molecular machinery involved in $\beta$-cell death, complex $\mathrm{Ca}^{2+}$ signaling has emerged as a significant contributor during these events and has gained significant attention. $\mathrm{Ca}^{2+}$ actively participates in various physiological processes within pancreatic $\beta$-cells and rapidly exchanges between the ER and mitochondria. The relationship between the changes in $\left(\mathrm{Ca}^{2+}\right)_{\mathrm{c}}$ and $\left(\mathrm{Ca}^{2+}\right)_{\mathrm{m}}$ during glucose stimulus was not completely understood. Extensive work has been done in these areas from last two decades to understand this intricate tethering between ER and Mitochondrial $\mathrm{Ca}^{2+}$ and their subsequent involvement in ATP regulation and insulin secretion [92-94]. Findings from these studies may provide a foundation upon which future experiments may be designed to identify specific pathways involved in inflammatory or metabolic dysfunction in the $\beta$-cell. These discoveries illuminate a more focused future on experiments designed to recognize other novel channels involved in $\mathrm{Ca}^{2+}$ signaling and mitochondrial dysfunction in $\beta$-cells. Such novel discoveries also hold promise for unravelling a novel mechanism to aid in the prevention of diabetes.

\section{Discussion and Future Prospects}

Over the years, it has been shown that PHBs interact with other signaling proteins to regulate a multitude of significant cellular events. We do not yet understand the mechanism through which PHBs regulate these events in both healthy and diabetic individuals. In the coming years, one of the biggest challenge's researchers studying diabetes will face is discovering new molecular targets for therapeutic intervention. Identifying the connecting link between $\mathrm{PHB}$ expression and $\mathrm{Ca}^{2+}$ signaling involved in the aetiology of metabolic diseases would do much to address this challenge and validate $\mathrm{PHB}$ as a potential therapeutic target. Nevertheless, emerging roles of mitochondrial-associated ER membranes (MAMs) in the regulation of $\mathrm{Ca}^{2+}$ homeostasis cannot be ruled out. MAMs play a crucial role in numerous signaling pathways and are still evolving [95-96]. However, the interaction of PHBs with MAMs has not been studied which could also be a worthy area of investigation.

Studying such interactions may lead to the development of potential drug targets for metabolic diseases. How PHBs influence $\left(\mathrm{Ca}^{2+}\right)_{c}$ and mitochondrial function are still not completely understood. Further studies designed to identify those mechanisms are worthy of investigation and could suggest a role of PHB in maintaining mitochondrial health.

\section{Conclusions}

The goal of this review is to better characterize $\mathrm{Ca}^{2+}$ effects on PHBs by directly examining how prohibitin handle $\mathrm{Ca}^{2+}$ in the mitochondria during diabetic pathophysiology. We emphasized on the most significant differences observed between control and PHBs knockdown in $\beta$-cells that should be indicative of the target of $\mathrm{Ca}^{2+}$ action, thereby establishing a biomarker for the detection of diabetic phenotype. This will also deliver an additional mechanistic approach to identify the most plausible targets for reversing $\mathrm{Ca}^{2+}$ induced damage during diabetes progression. Finally, understanding of this study will determine most substantial effects of $\mathrm{PHB}_{\mathrm{S}}$ in mitochondrial health and will inform the design of more targeted future experiments to reverse diabetes.

\section{Conflicts of Interest}

The authors (GV, $\mathrm{AD}$, and $\mathrm{CN}$ ) declare that there is no conflict of interest regarding the publication of this paper.

\section{Acknowledgments}

The author is thankful to the Company of Biologist, Journal of Cell Science, for providing travelling fellowship to perform a part of this study in the University of Virginia, United States, with Dr. Craig Nunemaker, Associate Professor, Medicine: Endocrinology and Metabolism, USA. The author is also thankful to Harsh Kumar, PhD, Regional Centre for Biotechnology, Faridabad, India for his critical inputs during the preparation of the manuscript.

\section{Supplementary Materials}

“Graphical Abstract”. (Supplementary materials)

\section{References}

[1] P. E. MacDonald, J. W. Joseph, and P. Rorsman, "Glucosesensing mechanisms in pancreatic $\beta$-cells," Philosophical Transactions of the Royal Society B: Biological Sciences, vol. 360, no. 1464, pp. 2211-2225, 2005.

[2] F. Perocchi, V. M. Gohil, H. S. Girgis et al., "MICU1 encodes a mitochondrial EF hand protein required for $\mathrm{Ca}^{2+}$ uptake," Nature, vol. 467, no. 7313, pp. 291-296, 2010.

[3] G. Szabadkai and M. R. Duchen, "Mitochondria: the hub of cellular $\mathrm{Ca}^{2+}$ signaling," Physiology (Bethesda), vol. 23, pp. 84-94, 2008.

[4] G. Szabadkai, A. M. Simoni, and R. Rizzuto, "Mitochondrial $\mathrm{Ca} 2+$ Uptake Requires Sustained Ca2+Release from the Endoplasmic Reticulum," The Journal of Biological Chemistry, vol. 278, no. 17, pp. 15153-15161, 2003.

[5] C. Cerella, M. Diederich, and L. Ghibelli, "The Dual Role of Calcium as Messenger and Stressor in Cell Damage, Death, and Survival," International Journal of Cell Biology, vol. 2010, Article ID 546163, 14 pages, 2010. 
[6] A. Carreras-Sureda, P. Pihán, and C. Hetz, "Calcium signaling at the endoplasmic reticulum: fine-tuning stress responses," Cell Calcium, vol. 70, pp. 24-31, 2018.

[7] R. Lemmens, O. Larsson, P. O. Berggren, and M. S. Islam, " $\mathrm{Ca}^{2+}$-induced $\mathrm{Ca}^{2+}$ release from the endoplasmic reticulum amplifies the $\mathrm{Ca}^{2+}$ signal mediated by activation of voltagegated L-type $\mathrm{Ca}^{2+}$ channels in pancreatic beta-cells," The Journal of Biological Chemistry, vol. 276, no. 13, pp. 9971-9977, 2001.

[8] T. Hara, J. Mahadevan, K. Kanekura, M. Hara, S. Lu, and F. Urano, "Calcium efflux from the endoplasmic reticulum leads to $\beta$-cell death," Endocrinology, vol. 155, no. 3, pp. 758-768, 2014.

[9] C. Klec, C. T. Madreiter-Sokolowski, S. Stryeck et al., "Glycogen Synthase Kinase 3 Beta Controls Presenilin-1-Mediated Endoplasmic Reticulum $\mathrm{Ca}^{2+}$ Leak Directed to Mitochondria in Pancreatic Islets and beta-Cells," Cellular Physiology and Biochemistry, vol. 52, no. 1, pp. 57-75, 2019.

[10] S. Mishra, L. Z. Murphy, and L. J. Murphy, "The Prohibitins: emerging roles in diverse functions," Journal of Cellular and Molecular Medicine, vol. 10, no. 2, pp. 353-363, 2006.

[11] F. Thuaud, N. Ribeiro, C. G. Nebigil, and L. Désaubry, "Prohibitin ligands in cell death and survival: mode of action and therapeutic potential," Chemistry \& Biology, vol. 20, no. 3, pp. 316-331, 2013.

[12] O. Van Aken, J. Whelan, and F. Van Breusegem, "Prohibitins: mitochondrial partners in development and stress response," Trends in Plant Science, vol. 15, no. 5, pp. 275-282, 2010.

[13] C. Osman, C. Merkwirth, and T. Langer, "Prohibitins and the functional compartmentalization of mitochondrial membranes," Journal of Cell Science, vol. 122, no. 21, pp. 38233830, 2009.

[14] T. Kang, W. Lu, W. Xu et al., "MicroRNA-27 (miR-27) targets prohibitin and impairs adipocyte differentiation and mitochondrial function in human adipose-derived stem cells," The Journal of Biological Chemistry, vol. 288, no. 48, pp. 34394-34402, 2013.

[15] A. L. Theiss and S. V. Sitaraman, "The role and therapeutic potential of prohibitin in disease," Biochimica et Biophysica Acta (BBA) - Molecular Cell Research, vol. 1813, no. 6, pp. 1137-1143, 2011.

[16] Y. T. Peng, P. Chen, R. Y. Ouyang, and L. Song, "Multifaceted role of prohibitin in cell survival and apoptosis," Apoptosis, vol. 20, no. 9, pp. 1135-1149, 2015.

[17] S. Manjeshwar, D. E. Branam, M. R. Lerner, D. J. Brackett, and E. R. Jupe, "Tumor suppression by the prohibitin gene 3'untranslated region RNA in human breast cancer," Cancer Research, vol. 63, no. 17, pp. 5251-5256, 2003.

[18] E. R. Jupe, X. T. Liu, J. L. Kiehlbauch, J. K. McClung, and R. T. Dell'Orco, “The 3' untranslated region of prohibitin and cellular immortalization," Experimental Cell Research, vol. 224, no. 1, pp. 128-135, 1996.

[19] M. A. Sanz, W. Y. Tsang, E. M. Willems et al., "The mitochondrial prohibitin complex is essential for embryonic viability and germline function inCaenorhabditis elegans," The Journal of Biological Chemistry, vol. 278, no. 34, pp. 32091-32099, 2003.

[20] L. G. J. Nijtmans, M. A. Sanz, L. A. Grivell, and P. J. Coates, "The mitochondrial PHB complex: roles in mitochondrial respiratory complex assembly, ageing and degenerative disease," Cellular and Molecular Life Sciences, vol. 59, no. 1, pp. 143-155, 2002.
[21] S. Mishra, "Phb1:Phb2 heterodimers in the mitochondria-beyond functional interdependence," Journal of Biological Chemistry, vol. 294, no. 40, p. 14836, 2019.

[22] T. Yoshinaka, H. Kosako, T. Yoshizumi et al., "Structural Basis of Mitochondrial Scaffolds by Prohibitin Complexes: Insight into a Role of the Coiled-Coil Region," iScience, vol. 19, pp. 1065-1078, 2019.

[23] J. D. Chavez, C. R. Weisbrod, C. Zheng, J. K. Eng, and J. E. Bruce, "Protein Interactions, Post-translational Modifications and Topologies in Human Cells," Mol Cell Proteomics, vol. 12, no. 5, pp. 1451-1467, 2013.

[24] M. Artal-Sanz and N. Tavernarakis, "Prohibitin and mitochondrial biology," Trends in Endocrinology and Metabolism, vol. 20, no. 8, pp. 394-401, 2009.

[25] T. Tatsuta, K. Model, and T. Langer, "Formation of membrane-bound ring complexes by prohibitins in mitochondria," Molecular Biology of the Cell, vol. 16, no. 1, pp. 248-259, 2005.

[26] S. Wang, N. Nath, G. Fusaro, and S. Chellappan, "Rb and prohibitin target distinct regions of E2F1 for repression and respond to different upstream signals," Molecular and Cellular Biology, vol. 19, no. 11, pp. 7447-7460, 1999.

[27] D. Choi, S.-J. Lee, S. Hong, I.-H. Kim, and S. Kang, "Prohibitin interacts with RNF2 and regulates E2F1 function via dual pathways," Oncogene, vol. 27, no. 12, pp. 1716-1725, 2008.

[28] W. Rizwani, M. G. Alexandrow, and S. P. Chellappan, "Prohibitin physically interacts with MCM proteins and inhibits mammalian DNA replication," Cell Cycle, vol. 8, no. 10, pp. 1621-1629, 2014.

[29] G. Fusaro, P. Dasgupta, S. Rastogi, B. Joshi, and S. Chellappan, "Prohibitin induces the transcriptional activity of p53 and is exported from the nucleus upon apoptotic signaling," The Journal of Biological Chemistry, vol. 278, no. 48, pp. 4785347861, 2003.

[30] E. R. Jupe, A. A. Badgett, B. R. Neas et al., "Single nucleotide polymorphism in prohibitin 3's untranslated region and breast-cancer susceptibility," Lancet, vol. 357, no. 9268, pp. 1588-1589, 2001.

[31] L. Sun, "Akt binds prohibitin 2 and relieves its repression of MyoD and muscle differentiation," Journal of Cell Science, vol. 117, no. 14, pp. 3021-3029, 2004.

[32] B. He, Q. Feng, A. Mukherjee et al., "A Repressive Role for Prohibitin in Estrogen Signaling," Molecular Endocrinology, vol. 22, no. 2, pp. 344-360, 2008.

[33] R. Delage-Mourroux, P. G. V. Martini, I. Choi, D. M. Kraichely, J. Hoeksema, and B. S. Katzenellenbogen, "Analysis of estrogen receptor interaction with a repressor of estrogen receptor activity (REA) and the regulation of estrogen receptor transcriptional activity by REA," The Journal of Biological Chemistry, vol. 275, no. 46, pp. 35848-35856, 2000.

[34] T. Agrawal, G. K. Gupta, and D. K. Agrawal, "Vitamin D deficiency decreases the expression of VDR and prohibitin in the lungs of mice with allergic airway inflammation," Experimental and Molecular Pathology, vol. 93, no. 1, pp. 74-81, 2012.

[35] X. Peng, R. Mehta, S. Wang, S. Chellappan, and R. G. Mehta, "Prohibitin is a novel target gene of vitamin D involved in its antiproliferative action in breast cancer cells," Cancer Research, vol. 66, no. 14, pp. 7361-7369, 2006.

[36] C. Merkwirth, S. Dargazanli, T. Tatsuta et al., "Prohibitins control cell proliferation and apoptosis by regulating OPA1- 
dependent cristae morphogenesis in mitochondria," Genes \& Development, vol. 22, no. 4, pp. 476-488, 2008.

[37] C. Merkwirth and T. Langer, "Prohibitin function within mitochondria: essential roles for cell proliferation and cristae morphogenesis," Biochimica et Biophysica Acta-Molecular Cell Research, vol. 1793, no. 1, pp. 27-32, 2009.

[38] K. Kasashima, E. Ohta, Y. Kagawa, and H. Endo, "Mitochondrial functions and estrogen receptor-dependent nuclear translocation of pleiotropic human prohibitin 2," The Journal of Biological Chemistry, vol. 281, no. 47, pp. 36401-36410, 2006.

[39] G. Fusaro, S. Wang, and S. Chellappan, "Differential regulation of $\mathrm{Rb}$ family proteins and prohibitin during camptothecininduced apoptosis," Oncogene, vol. 21, no. 29, pp. 4539-4548, 2002.

[40] J. Yang, B. Li, and Q. Y. He, "Significance of prohibitin domain family in tumorigenesis and its implication in cancer diagnosis and treatment," Cell Death \& Disease, vol. 9, no. 6, p. 580, 2018.

[41] S. Rastogi, B. Joshi, G. Fusaro, and S. Chellappan, "Camptothecin induces nuclear export of prohibitin preferentially in transformed cells through a CRM-1-dependent mechanism," Journal of Biological Chemistry, vol. 281, no. 5, pp. 29512959, 2006.

[42] C. Merkwirth, P. Martinelli, A. Korwitz et al., "Loss of prohibitin membrane scaffolds impairs mitochondrial architecture and leads to tau hyperphosphorylation and neurodegeneration," PLoS Genetics, vol. 8, no. 11, article e1003021, 2012.

[43] K. Kasashima, M. Sumitani, M. Satoh, and H. Endo, "Human prohibitin 1 maintains the organization and stability of the mitochondrial nucleoids," Experimental Cell Research, vol. 314, no. 5, pp. 988-996, 2008.

[44] X. J. Chen and R. A. Butow, "The organization and inheritance of the mitochondrial genome," Nature Reviews. Genetics, vol. 6, no. 11, pp. 815-825, 2005.

[45] D. J. Lefer and D. N. Granger, "Oxidative stress and cardiac disease," The American Journal of Medicine, vol. 109, no. 4, pp. 315-323, 2000.

[46] J. W. Baynes, "The role of AGEs in aging: causation or correlation," Experimental Gerontology, vol. 36, no. 9, pp. 1527-1537, 2001.

[47] F. Lupoli, T. Vannocci, G. Longo, N. Niccolai, and A. Pastore, "The role of oxidative stress in Friedreich's ataxia," FEBS Letters, vol. 592, no. 5, pp. 718-727, 2018.

[48] M. Kakarla, V. K. Puppala, S. Tyagi et al., "Circulating levels of mitochondrial uncoupling protein 2, but not prohibitin, are lower in humans with type 2 diabetes and correlate with brachial artery flow-mediated dilation," Cardiovascular Diabetology, vol. 18, no. 1, p. 148, 2019.

[49] K. S. Echtay, D. Roussel, J. St-Pierre et al., "Superoxide activates mitochondrial uncoupling proteins," Nature, vol. 415, no. 6867 , pp. 96-99, 2002.

[50] L. G. J. Nijtmans, "Prohibitins act as a membrane-bound chaperone for the stabilization of mitochondrial proteins," The EMBO Journal, vol. 19, no. 11, pp. 2444-2451, 2000.

[51] J. P. Castro, K. Wardelmann, T. Grune, and A. Kleinridders, "Mitochondrial chaperones in the brain: safeguarding brain health and metabolism?," Frontiers in Endocrinology, vol. 9, 2018.

[52] X. H. Liu, Z. Ren, R. Zhan et al., "Prohibitin protects against oxidative stress-induced cell injury in cultured neonatal car- diomyocyte," Cell Stress \& Chaperones, vol. 14, no. 3, pp. 311-319, 2009.

[53] B. Zhu, J. Zhai, H. Zhu, and N. Kyprianou, "Prohibitin regulates TGF-beta induced apoptosis as a downstream effector of Smad-dependent and -independent signaling," Prostate, vol. 70, no. 1, pp. 17-26, 2010.

[54] Y.-H. Liu, K. Peck, and J.-Y. Lin, "Involvement of Prohibitin Upregulation in Abrin-Triggered Apoptosis," Evidence-Based Complementary and Alternative Medicine, vol. 2012, Article ID 605154, 11 pages, 2012.

[55] D. E. Clapham, "Calcium signaling," Cell, vol. 80, no. 2, pp. 259-268, 1995.

[56] B. F. Trump and I. K. Berezesky, "Calcium-mediated cell injury and cell death," The FASEB Journal, vol. 9, no. 2, pp. 219-228, 1995.

[57] M. J. Berridge, M. D. Bootman, and P. Lipp, "Calcium-a life and death signal,” Nature, vol. 395, no. 6703, pp. 645-648, 1998.

[58] G. Cao, J. van der Wijst, A. M. van der Kemp, F. van Zeeland, R. J. Bindels, and J. G. Hoenderop, "Regulation of the epithelial $\mathrm{Mg}^{2+}$ channel TRPM6 by estrogen and the associated repressor protein of estrogen receptor activity (REA)," Journal of Biological Chemistry, vol. 284, no. 22, pp. 14788-14795, 2009.

[59] G. Verma, H. Bhatia, and M. Datta, "JNK1/2 regulates ERmitochondrial Ca2+cross-talk during IL- $1 \beta$-mediated cell death in RINm5F and human primary $\beta$-cells," Molecular Biology of the Cell, vol. 24, no. 12, pp. 2058-2071, 2013.

[60] E. Lai, T. Teodoro, and A. Volchuk, "Endoplasmic reticulum stress: signaling the unfolded protein response," Physiology (Bethesda), vol. 22, pp. 193-201, 2007.

[61] N. R. Johnston, R. K. Mitchell, E. Haythorne et al., "Beta cell hubs dictate pancreatic islet responses to glucose," Cell Metabolism, vol. 24, no. 3, pp. 389-401, 2016.

[62] S. B. Dula, M. Jecmenica, R. Wu et al., "Evidence that lowgrade systemic inflammation can induce islet dysfunction as measured by impaired calcium handling," Cell Calcium, vol. 48, no. 2-3, pp. 133-142, 2010.

[63] B. Wacquier, L. Combettes, G. T. van Nhieu, and G. Dupont, "Interplay between intracellular $\mathrm{Ca}^{2+}$ oscillations and $\mathrm{Ca}^{2+}$ stimulated mitochondrial metabolism," Scientific Reports, vol. 6 , no. 1, 2016.

[64] J. Maleth and P. Hegyi, "Ca ${ }^{2+}$ toxicity and mitochondrial damage in acute pancreatitis: translational overview," Philosophical Transactions of the Royal Society B-Biological Sciences, vol. 371, no. 1700, p. 20150425, 2016.

[65] G. A. Rutter and R. Rizzuto, "Regulation of mitochondrial metabolism by $\mathrm{ER} \mathrm{Ca}^{2+}$ release: an intimate connection," Trends in Biochemical Sciences, vol. 25, no. 5, pp. 215-221, 2000.

[66] J. V. Gerasimenko, O. Gryshchenko, P. E. Ferdek et al., " $\mathrm{Ca}^{2+}$ release-activated $\mathrm{Ca}^{2+}$ channel blockade as a potential tool in antipancreatitis therapy," PNAS, vol. 110, no. 32, pp. 1318613191, 2013.

[67] P. Delmotte and G. C. Sieck, "Interaction between endoplas$\mathrm{mic} /$ sarcoplasmic reticulum stress (ER/SR stress), mitochondrial signaling and $\mathrm{Ca}^{2+}$ regulation in airway smooth muscle (ASM)," Canadian Journal of Physiology and Pharmacology, vol. 93, no. 2, pp. 97-110, 2015.

[68] S. Supale, F. Thorel, C. Merkwirth et al., "Loss of prohibitin induces mitochondrial damages altering $\beta$-cell function and survival and is responsible for gradual diabetes development," Diabetes, vol. 62, no. 10, pp. 3488-3499, 2013. 
[69] M. Hara, V. Bindokas, J. P. Lopez et al., "Imaging endoplasmic reticulum calcium with a fluorescent biosensor in transgenic mice," American Journal of Physiology-Cell Physiology, vol. 287, no. 4, pp. C932-C938, 2004.

[70] D. B. Zorov, E. Kobrinsky, M. Juhaszova, and S. J. Sollott, "Examining intracellular organelle function using fluorescent probes - from animalcules to quantum dots," Circulation Research, vol. 95, no. 3, pp. 239-252, 2004.

[71] J. Suzuki, K. Kanemaru, and M. Iino, "Genetically encoded fluorescent indicators for organellar calcium imaging," Biophysical Journal, vol. 111, no. 6, pp. 1119-1131, 2016.

[72] T. Gutiérrez and T. Simmen, "Endoplasmic reticulum chaperones tweak the mitochondrial calcium rheostat to control metabolism and cell death," Cell Calcium, vol. 70, pp. 64-75, 2018.

[73] E. F. Corbett, K. Oikawa, P. Francois et al., "Ca ${ }^{2+}$ regulation of interactions between endoplasmic reticulum chaperones," Journal of Biological Chemistry, vol. 274, no. 10, pp. 62036211, 1999.

[74] A. Messina, S. Reina, F. Guarino et al., "Live cell interactome of the human voltage dependent anion channel 3 (VDAC3) revealed in HeLa cells by affinity purification tag technique," Molecular BioSystems, vol. 10, no. 8, pp. 2134-2145, 2014.

[75] L. Halperin, J. Jung, and M. Michalak, "The many functions of the endoplasmic reticulum chaperones and folding enzymes," IUBMB Life, vol. 66, no. 5, pp. 318-326, 2014.

[76] D. Wang, R. Tabti, S. Elderwish et al., "Prohibitin ligands: a growing armamentarium to tackle cancers, osteoporosis, inflammatory, cardiac and neurological diseases," Cellular and Molecular Life Sciences, vol. 77, no. 18, pp. 3525-3546, 2020.

[77] M. Whitaker, "Genetically encoded probes for measurement of intracellular calcium," Calcium in Living Cells, vol. 99, pp. 153-182, 2010.

[78] K. Rajalingam, C. Wunder, V. Brinkmann et al., "Prohibitin is required for Ras-induced Raf-MEK- ERK activation and epithelial cell migration," Nature Cell Biology, vol. 7, no. 8, pp. 837-843, 2005.

[79] Z. Luan, Y. He, M. Alattar, Z. Chen, and F. He, "Targeting the prohibitin scaffold-CRAF kinase interaction in RAS-ERKdriven pancreatic ductal adenocarcinoma," Molecular Cancer, vol. 13, no. 1, p. 38, 2014.

[80] S. R. Ande, Y. Gu, B. L. G. Nyomba, and S. Mishra, "Insulin induced phosphorylation of prohibitin at tyrosine114 recruits Shp1," Biochimica et Biophysica Acta, vol. 1793, no. 8, pp. 1372-1378, 2009.

[81] J. L. Evans, I. D. Goldfine, B. A. Maddux, and G. M. Grodsky, "Are oxidative stress-activated signaling pathways mediators of insulin resistance and $\beta$-cell dysfunction?," Diabetes, vol. 52, no. 1, pp. 1-8, 2003.

[82] Y. Miyazaki, H. Kawano, T. Yoshida et al., "Pancreatic B-cell function is altered by oxidative stress induced by acute hyperglycaemia," Diabetic Medicine, vol. 24, no. 2, pp. 154-160, 2007.

[83] J. H. Lee, K. H. Nguyen, S. Mishra, and B. L. Nyomba, "Prohibitin is expressed in pancreatic beta-cells and protects against oxidative and proapoptotic effects of ethanol," FEBS Journal, vol. 277, no. 2, pp. 488-500, 2010.

[84] K. Medler and E. L. Gleason, "Mitochondrial $\mathrm{Ca}^{2+}$ buffering regulates synaptic transmission between retinal amacrine cells," Journal of Neurophysiology, vol. 87, no. 3, pp. 14261439, 2002.

[85] G. Zhu and A. S. Lee, "Role of the unfolded protein response, GRP78 and GRP94 in organ homeostasis," Journal of Cellular Physiology, vol. 230, no. 7, pp. 1413-1420, 2015.

[86] M. Michalak, J. M. Robert Parker, and M. Opas, " $\mathrm{Ca}^{2+}$ signaling and calcium binding chaperones of the endoplasmic reticulum," Cell Calcium, vol. 32, no. 5-6, pp. 269-278, 2002.

[87] C. Giorgi, S. Marchi, and P. Pinton, "The machineries, regulation and cellular functions of mitochondrial calcium," Nature Reviews. Molecular Cell Biology, vol. 19, no. 11, pp. 713-730, 2018.

[88] V. Paupe and J. Prudent, "New insights into the role of mitochondrial calcium homeostasis in cell migration," Biochemical and Biophysical Research Communications, vol. 500, no. 1, pp. 75-86, 2018.

[89] S. R. Ande, K. H. Nguyen, G. P. Padilla-Meier, W. Wahida, B. L. G. Nyomba, and S. Mishra, "Prohibitin overexpression in adipocytes induces mitochondrial biogenesis, leads to obesity development, and affects glucose homeostasis in a sexspecific manner," Diabetes, vol. 63, no. 11, pp. 3734-3741, 2014.

[90] K. H. Nguyen, S. R. Ande, and S. Mishra, "Obesity-related abnormalities couple environmental triggers with genetic susceptibility in adult-onset T1D," Biochemical and Biophysical Research Communications, vol. 470, no. 1, pp. 94-100, 2016.

[91] J. K. McClung, E. R. Jupe, X.-T. Liu, and R. T. Dell'Orco, “Prohibitin: potential role in senescence, development, and tumor suppression," Experimental Gerontology, vol. 30, no. 2, pp. 99-124, 1995.

[92] A. I. Tarasov, F. Semplici, D. Li et al., "Frequency-dependent mitochondrial $\mathrm{Ca}^{2+}$ accumulation regulates ATP synthesis in pancreatic $\beta$ cells," Pflügers Archiv - European Journal of Physiology, vol. 465, no. 4, pp. 543-554, 2013.

[93] G. A. Rutter, D. J. Hodson, P. Chabosseau, E. Haythorne, T. J. Pullen, and I. Leclerc, "Local and regional control of calcium dynamics in the pancreatic islet," Diabetes, Obesity and Metabolism, vol. 19, pp. 30-41, 2017.

[94] C. Klec, G. Ziomek, M. Pichler, R. Malli, and W. F. Graier, "Calcium signaling in $ß$-cell physiology and pathology: a revisit," International Journal of Molecular Sciences, vol. 20, no. 24, p. 6110, 2019.

[95] C. T. M. Sokolowski, R. Malli, and W. F. Graier, "Mitochondrial-Endoplasmic Reticulum Interplay: A Lifelong On-Off Relationship?," Contact (Thousand Oaks), vol. 2, article 251525641986122, 2019.

[96] G. Szabadkai, K. Bianchi, P. Várnai et al., "Chaperone-mediated coupling of endoplasmic reticulum and mitochondrial Ca2+ channels," Journal of Cell Biology, vol. 175, no. 6, pp. 901-911, 2006. 